\title{
Maintaining Tacit Collusion in Repeated Ascending Auctions
}

\author{
Owen R. Phillips University of Wyoming \\ Dale J. Menkhaus University of Wyoming
}

\begin{abstract}
In a repeated two-stage game, identical goods are produced and then sold through an ascending auction. Baseline market structures are created in the laboratory with a fixed number of units sold, and either two or four buyers bid as each unit is offered for sale. Bidding rings develop in both auction environments. Three "seller-active" market structures are created in which sellers individually and repeatedly decide how many units to produce and bring to an auction. Auction designs have two or four sellers and two or four buyers. Bidding rings develop in two-buyer markets but falter because sellers reduce production sufficiently to destabilize the ring. Bids rise to the equilibrium at the intersection of supply and demand. Prices are higher when there are four buyers. Sellers can tacitly coordinate through the advance production decision.
\end{abstract}

\section{Introduction}

A market environment in which suppliers sequentially produce a quantity and then sell it at an auction is the purest form of a Cournot market (Kreps and Scheinkman 1983). Collectively, sellers have a supply schedule and buyers have a demand schedule. In the first stage of a two-stage game, sellers make a binding production decision. In the second stage, this inventory is sold through an auctioneer. ${ }^{1}$ We find this setting to be a realistic description of how many products are sold. There is the repeated advance production and auction sale of timber (Athey, Levin, and Seira 2004), automobiles (Nelson 1995), cotton, tobacco, cattle (Phillips, Menkhaus, and Coatney 2003), wines, antiques, and artwork

\footnotetext{
Kalyn Coatney and Gerhard Hambusch provided excellent assistance in conducting the laboratory experiments. Many helpful comments were received from participants at the 2006 Experimental Science meetings in Tucson, Arizona, and the Law and Economics seminar at Vanderbilt University. The editors and referee have provided valuable insights on submitted drafts. Research support from the Paul Lowham Research Fund is gratefully acknowledged. Any opinions, findings, conclusions, or recommendations expressed in this paper are those of the authors and do not necessarily reflect the views of the funding source.

${ }^{1}$ The main point of Kreps and Scheinkman (1983) is that an auctioneer is not even needed in the second stage. Sellers could undertake Bertrand-like price competition and the equilibrium would still be Cournot as long as there was production in the first stage.

[Journal of Law and Economics, vol. 52 (February 2009)]

(C) 2009 by The University of Chicago. All rights reserved. 0022-2186/2009/5201-0005\$10.00
} 
(Ashenfelter 1989; Ashenfelter and Grady 2003). In livestock markets, cattle are frequently sold at auction barns on a weekly basis. Sellers truck their stock to the site, where an English auction is conducted. ${ }^{2}$ Some auction days are busier than others, but cattle are repeatedly sold at regional auction barns during selected days of a week, virtually every week of the year. Often the same buyers, who may be processors or agents for meat processors, attend these auctions.

Repeated interaction facilitates cooperation. A bidding ring is a coalition of buyers who effectively act as a single bidder at an auction. ${ }^{3}$ Rings need not be formal organizations. Members may simply alternate submitting the low bid for successive items. For rings with limited contact among members, or if ring members face a threat of prosecution, this could be a sharing mechanism that is focal. Bidding rings seem to be commonplace in ascending auctions. With respect to English auctions, Graham and Marshall (1987, p. 1221) write, "So prevalent are rings, in fact, that a retired auctioneer once noted that in 40 years of auctioneering, he had yet to attend an auction at which a ring was not present." In sealed-bid auctions, Porter and Zona $(1993,1999)$ report bid-rigging practices at a number of procurement auctions and in the provision of milk to school lunch programs. Recently, Athey, Levin, and Seira (2004) discovered evidence of bidding rings among mills at timber auctions.

Collusive tendencies have been reported in a variety of experimental auction markets. For instance, Li and Plott (2005) gave eight buyers full information on payoffs, bids, and buyer identities as they simultaneously bid on eight objects in a repeated ascending auction. Agents quickly learned to collude by giving each other the item they valued the greatest and letting winning bids stay low. Collusion continued after information about other bidders was removed. Sherstyuk (2003) provides a survey of her work and other recent work on anticompetitive behavior in multiunit ascending auctions. She finds evidence of market splitting in simultaneous, multiunit, ascending auctions. If bid improvement rules are modified so that bidders can match a high bid and collectively win a split of what is being auctioned, bidders converge to a common and low bid. If bidders know the numbers of units that will be sold at auction and there is no endogenous production, bidding rings can be observed in a laboratory setting for two and six bidders, depending on communication (Phillips, Menkhaus, and Coatney 2003).

As items are being auctioned, the success of a ring can be countered by the seller or auctioneer setting a reserve (or minimum) price at which the item sells.

\footnotetext{
${ }^{2}$ More accurately, the format is a single-sided open-outcry auction. Bidders may jump the bids of others and exit and enter during the bidding. Several authors describe an English auction as an ascending auction for which bidders keep their finger on a button that marginally increases bids. Bidders drop out by releasing the button. The last bidder pays the final dropout bid. After exit, there is no reentry. Milgrom and Weber (1982) rely on this latter design in their framework and describe it as a Japanese-English auction. Graham and Marshall (1987) call it an English thermometer auction.

${ }^{3}$ Graham and Marshall (1987) describe a ring or "kipper" as $K$ of $N$ bidders $(2 \leq K \leq N)$ removing $K-1$ bidders from competitively bidding. If the ring wins the item, there may be a secondary auction known as a "knockout" to decide who in the ring gets the item.
} 
Graham and Marshall (1987) and McAfee and McMillan (1992) show that the reserve level should increase with the size of the ring. If all buyers are in the ring, the reserve price becomes the seller's offer price, and the ring accepts or rejects the reserve offer. The auction reduces to repeated bilateral bargaining. The auctioneer also can recognize phantom bids (a practice called "lift lining") or actually install confederates among the bidders to boost winning bids. These counteractions against bidding rings create some probability that the auction house will buy the product, so the house or the seller must be prepared to keep the good. Familiarity among bidders makes it more difficult for the auctioneer to generate false bids. If lift-lining practices are discovered, the ring can stop bidding and leave the seller with large quantities of unsold goods.

This paper argues that if the two-stage game is repeated and trading is preceded by a production stage, uncoordinated producers will cut back on the number of units produced in response to low bids from the ring. Marginal values become high relative to the winning bid. This puts pressure on individual ring members to bid higher, and the stability of the ring is threatened. The reduction in units supplied by producers is a very natural response to low bids, and we show in experimental markets that it is a robust response to bidding rings. It is a far less strategic response, compared to setting and adjusting reserve prices or lift lining. We note there is a considerable amount of information needed to set reserve prices. Graham and Marshall (1987), Myerson (1981), and Riley and Samuelson (1981) show that along with the bidder's demand schedule, sellers must know the distribution function of bids and the number of bidders in the ring. It is altogether easier for individual sellers to observe low bid prices and produce less in the next period.

\section{Theoretical Considerations}

A bidding ring has a problem when there is endogenous production. It wants to keep bids low, but low bids make suppliers cut back on the quantity brought to market in future periods. Bids at the reserve (or a zero) price would mean no production of the good in later periods. Positive but low production of the good increases the probability of ring members cheating on the agreement. At the margin, the value of the object is higher when relatively few items are sold. This increases the likelihood of ring members breaking away from an agreement and bidding at higher levels out of turn. There must be a balance between keeping bids low and minimizing the probability of cheating. The following model describes the problem faced by a bidding ring.

We use the following notation:

$b=$ the winning bid allowed by a bidding ring for its members; $f(b)=$ probability of maintaining the collusive agreement among ring members, $\partial f(b) / \partial b>0$; 
$\pi^{\mathrm{C}}(b)=$ collusive profits of a typical ring member; these are a function of bids, $\partial \pi \mathrm{C} / \partial b<0$;

$\pi=$ profits of a typical ring member when there is no agreement to keep bids low;

$\delta=$ discount factor;

$n=$ number of bidding ring members; and

$q=$ number of units available for sale at the auction.

The bidding ring wants to maximize expected profits $(\bar{\pi})$ for a typical ring member. The objective is

$$
\max _{b} \bar{\pi}=f(b)(1+\delta) \pi^{\mathrm{C}}(b)+[1-f(b)](0+\delta \pi) .
$$

The second term on the right-hand side represents expected discounted profits when the bidding ring has collapsed and buyers bid up to their highest marginal value. Zero profits in the current period result from a ring member getting outbid by another member bidding out of turn. Without loss of generality, let $\pi=0$. Then the objective is

$$
\max _{b} \bar{\pi}=f(b)(1+\delta) \pi^{\mathrm{C}}(b) .
$$

The necessary first-order condition is

$$
\frac{\partial \bar{\pi}}{\partial b}=(1+\delta) \frac{\partial f(b)}{\partial b} \pi^{\mathrm{C}}+(1+\delta) f(b) \frac{\partial \pi^{\mathrm{C}}}{\partial b}=0 .
$$

Assume that $\partial \pi \mathrm{C} / \partial b=-q / n$, where $n$ is the number of bidding ring members and $q$ is the total number of units auctioned. For every $\$ 1$ increase in a bid, the profits of a bidder fall by the bidder's $q / n$ share of purchases.

The first-order condition becomes

$$
\frac{\partial f(b)}{\partial b} \pi^{\mathrm{C}}+f(b)\left(-\frac{q}{n}\right)=0,
$$

and defining $\epsilon_{f b}$ as the elasticity of the probability of cooperation in the ring as bids change, an implicit solution for $b$ can be written as

$$
b=\frac{n}{q} \pi^{\mathrm{C}} \epsilon_{f b}>0 .
$$

This expression describes a collusive bid that is positive or above the reserve price. Clearly there are a number of empirical propositions suggested. For example, the collusive bid is larger in $n$ and $\pi^{\mathrm{C}}$. If a bidding ring has a large membership or makes large returns, the probability of cheating increases, so bids are kept relatively high to reduce the gains from cheating and to maintain the 
ring. ${ }^{4}$ Important to our work, the collusive bid is small in q; in a dynamic setting when sellers can respond to low bids by producing less in later auctions, this has some probability of destabilizing the ring, and collusive bids must increase. We demonstrate this basic proposition in repeated laboratory English auctions.

\section{Experimental Market Conditions and Structures}

In our laboratory setting, tacit bidding rings are allowed to naturally evolve, and their stability is compared in two distinct market environments. In a benchmark auction setting, buyers with identical demand schedules are told that a constant number of units will be auctioned. The number never changes for a fixed number of repeated auctions. Sellers have no active role in this design. These English auctions are conducted for two buyers and four buyers, bidding on identical fictitious goods brought up for sale one unit at a time. These auction experiments are referred to as "seller inactive." In a second environment, sellers are given a role and individually decide over a series of repeated auctions how many units to bring to each auction. These auctions are referred to as "seller active." Before bidding begins, buyers are told how many units will be sold. Buyer collusion is fostered in our laboratory English auctions when the number of buyers is restricted and the total number of units available is known before bidding begins. In the seller-active auctions, outcomes in several buyer/seller configurations are reported. The auction design is conducted for two buyers and four sellers, four buyers and four sellers, and four buyers and two sellers.

The underlying supply and demand conditions in all of the auction experiments are very simple and are illustrated in Figure 1. The individual supply schedule has the approximate linear form $p=25+10 q$. The individual demand schedule is approximated by $p=135-10 q$. A market with four buyers and four sellers operating at the intersection of supply and demand (the competitive equilibrium) would exhibit an equilibrium price of 80 tokens and sales between 20 and 24 units. Predicted earnings for each of the four buyers and sellers are equal at 150 tokens; total surplus or the combined earnings of all traders is 1,200 tokens.

The Kreps and Scheinkman (1983) proposition is that advance production in either a quantity- or price-choosing game will generate Cournot outcomes. It is straightforward to solve for the symmetric Cournot quantities and prices $\left(Q_{c i}\right.$ and $\left.P_{c i}\right)$ when there are four sellers $(i=4)$ each effectively operating one production plant and also for two sellers $(i=2)$ each operating two plants. The Cournot market quantity and price with four sellers are $Q_{c 4}=19.56$ units and $P_{c 4}=86.11$ tokens. Individual seller and buyer earnings in this case are expected to be 178.78 tokens and 119.02 tokens, respectively. Total combined earnings for all agents are 1,191.20 tokens. The Cournot market quantity and price for

\footnotetext{
${ }^{4}$ In order for $d b / d n>0$, there are restrictions on $\partial^{2} f(b) / \partial b^{2}$. If $\pi^{\mathrm{C}} \geq 0$ then $\partial^{2} f(b) / \partial b^{2} \leq 0$ is sufficient for a positive relation between $b$ and $n$. The same restriction exists for sufficiency in the secondorder condition. We thank Paul Edelman for pointing this out.
} 


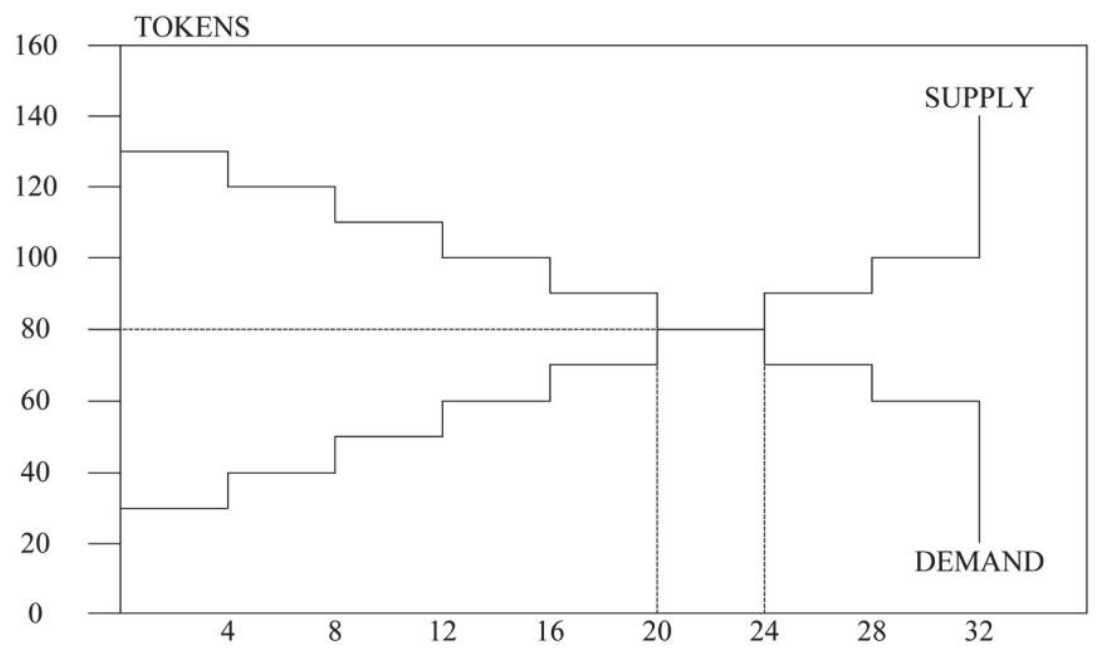

Figure 1. Induced market supply and demand

two sellers each with production from two plants are $Q_{\mathrm{c} 2}=17.60$ and $P_{\mathrm{c} 2}=$ 91.00. Sellers are predicted to earn 192.40 tokens at each production plant, and buyers are expected to earn 95.60 each. Total earnings equal 1,152 tokens.

A single monopoly operating four production facilities in the market will sell $Q_{\mathrm{m}}=15.33$ and set a price $P_{\mathrm{m}}=96.67$. Earnings for each seller and buyer are 200.69 and 72.51 tokens, respectively, and total earnings are estimated to be $1,092.80$ tokens. This is the collusive case in which sellers join together and behave like a monopolist. This outcome is a possibility in the two-seller market configuration and is provided for reference when the data are described below.

In our laboratory market, each seller was given a schedule that specified the marginal cost of each unit produced. Sellers made a profit if the unit was sold for more than its unit cost. Each schedule represented a production plant. Buyers were given a redemption schedule that specified the resale value of each unit purchased. These resale values induced demand. Buyers made money (consumer surplus) if they bought at prices less than their redemption values. Unit costs and redemption values that correspond to Figure 1 are provided in Table 1.

The experiments repeated 10 English auctions in each session. In the benchmark seller-inactive design, buyers were instructed that 20 units would be sold at each auction and that this amount would not vary. In the seller-active design, each auction period had two phases, a production phase during which each seller chose the number of units to produce and a trading phase, which was the ascending auction. Sellers paid all costs of production before units came up for sale. After all produced units were sold, a new auction period began, with sellers deciding how much to produce for the next sale. During the auction, sellers observed the sale of each unit. Lowest cost units were offered first, and a seller 
Table 1

Unit Values and Unit Costs (in Tokens)

\begin{tabular}{lcc}
\hline Unit(s) & Values (Buyers) & Costs (Sellers) \\
\hline 1 & 130 & 30 \\
2 & 120 & 40 \\
3 & 110 & 50 \\
4 & 100 & 60 \\
5 & 90 & 70 \\
6 & 80 & 80 \\
7 & 70 & 90 \\
8 & 60 & 100 \\
\hline
\end{tabular}

knew when his or her unit was being sold. This trading phase of the experiment took some time. Repeating 10 auctions with their production phases took up to 3 hours. The seller-active laboratory market duplicated a market setting for which units are produced and brought to a site where the seller can observe the bidding behavior on every unit purchased. The numbers of units brought to the auction for sale were known. This was like a repeated wine, cattle, or auto auction or repeated eBay auctions for numerous items produced and auctioned.

Redemption values were identical for each buyer, and production costs were identical for each seller. Subjects were not told about supply and demand in the market as described by Figure 1, and they were not told that the agents were identical. The laboratory instructions, as appropriate for the two auction designs, identified each subject as either a buyer or a seller, provided each person with a cost or redemption schedule, and described a production-trading cycle with an emphasis on how to earn money.

At the beginning of an experiment, each participant was given an initial balance of $\$ 10.00$. This balance was necessary to cover production costs for active sellers prior to the auction. Buyers were also given a $\$ 10.00$ balance for consistency. For a buyer, earnings on each unit purchased equaled the redemption value of the particular unit less the price paid to the seller. For a seller, earnings on each unit sold equaled the price received by the seller less the production cost of the unit. Earnings accumulated over the sequence of auction cycles, and at the end of each cycle they were displayed to each participant on his or her computer screen. At the conclusion of an experiment, participants were paid in cash. Average earnings were about $\$ 25.00$.

In the auction, buyers could bid by clicking up on a bid button displayed on the computer screen. Each click was a penny (1 token) increment. Buyers could increase bids more by typing in a specific bid. A buyer's screen flashed "Going once, going twice, Sold!" if no bids were submitted after a 3-second pause in activity. Bidding continued until all units were sold. In all sessions, the bidding began at 60 tokens. If buyers did not enter a bid, the bid price dropped by 5 tokens every 3 seconds until it hit a reserve price of 40 . At the reserve price, the item was taken off the market and the next item was offered. An unsold unit became a sunk cost to the seller. 
Results from five auction market environments are reported. Basic market conditions were always kept fixed; that is, supply and demand conditions illustrated in Figure 1 did not change. The seller-inactive auctions with a constant number of units sold are referenced as $2 \mathrm{~B}$ and $4 \mathrm{~B}$, respectively, for two buyers and four buyers bidding. Five sessions were conducted for the $2 \mathrm{~B}$ design, and two sessions were conducted for the $4 \mathrm{~B}$ design. In the seller-active auction design, four buyers and four sellers are referenced as 4B4S, two buyers and four sellers are $2 \mathrm{~B} 4 \mathrm{~S}$, and four buyers and two sellers are referred to as $4 \mathrm{~B} 2 \mathrm{~S}$. Each of these auction settings was replicated three times.

\section{Data Summary}

We provide a quick sketch of the seller-inactive results. Aggregating replications and reporting average prices, Figure 2 illustrates the average selling price for each of the 10 periods; in each period a constant 20 units are brought to market. In the $2 \mathrm{~B}$ design, the average selling price begins at just under 53 tokens and then rises a bit before settling at a price between 50 and 51 tokens. Buyers are coordinated enough to let price drop from the auctioneer's opening price of 60 and exchange winning bids at about the halfway point between the opening bid and the reserve price. Behavior remains stable through 10 repeated auction cycles. We have found similar bidding ring behavior in other repeated auction settings (Phillips, Menkhaus, and Coatney 2003). Behavior is not so coordinated in the $4 \mathrm{~B}$ auction designs, but the average winning bids as reported in Figure 2 show evidence of coordinated behavior. There is instability in the winning bids for the first four auction cycles, but after this, prices settle to amounts between 60 and 70 tokens. All prices in these auction environments are well below the price of 80 tokens at the intersection of supply and demand.

Strong evidence of collusion is surprising in light of a rich history of auction theory and experimental testing that support quick convergence of price to the intersection of supply and demand (see Kagel 1995). The standard auction theory and related testing have not constructed environments with repeated interaction that allow tacit agreements to develop. We have conducted seller-inactive experiments with repeated interaction, however, that make it more difficult to cooperate. For example, with the same basic market conditions, if buyers have no information on the number of units being auctioned, prices are competitive. In our auction designs, the number of buyers and sellers is common knowledge, but having an unknown number of buyers makes bidding more competitive. Knowing the last trading cycle damages cooperation. The degree to which these pieces of information exist in actual repeated and ascending auctions will affect the success of a bidding ring. In the simultaneous and repeated bidding on two objects, Kwasnica and Sherstyuk (2007) have reported collusive behavior when there are just two bidders and sellers are inactive. They find that buyers coordinate their winning bids in about 27 percent of their auctions. Strong complemen- 


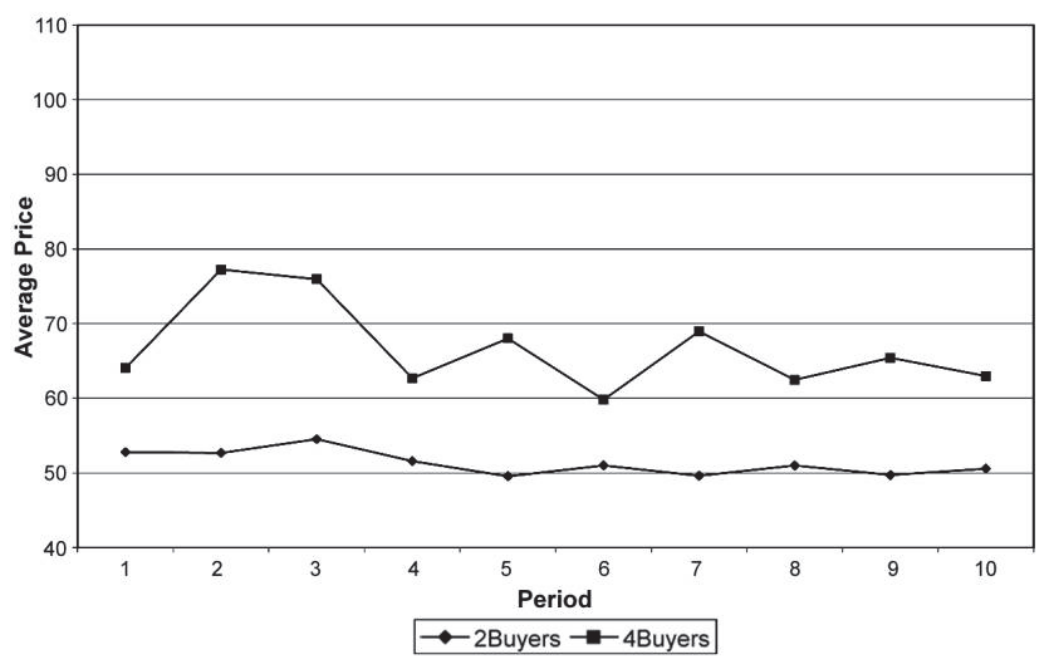

Figure 2. Average prices in auctions with two and four buyers and exogenous production.

tarities between the items, which essentially collapse bidding to one object, and/ or going to five buyers destroys coordination.

Again aggregating replications, we summarize the data in the seller-active auctions by graphing average prices, trades, and earnings for the 10 auction periods. At the end of each plot, convergence or asymptote (denoted "asy") estimates are provided from a model described in the next section. These values offer some indication of where averages are going should the experiment continue. They are a weighted average of past values, where later values get increased weight. A trend in the last half of an experiment or during the last few periods is tempered by earlier values.

Figure 3 describes average selling prices of items sold by auction design. It is worth observing that for the market designs that have four buyers (4B4S, 4B2S), prices hold steady in the 90-105 token range over the 10 periods. Over all 10 auction cycles, prices are higher than the 80 tokens predicted by the intersection of supply and demand and higher than the Cournot price for four sellers (86.11 tokens). For all of the 10 cycles, prices are higher when there are two sellers (4B2S) producing than when there are four sellers producing (4B4S). Toward the end of the experimental sessions, prices from the two $4 \mathrm{~B}$ designs tend to be bound by the Cournot price for two sellers and the collusive monopoly predicted values: 91 and about 97 tokens, respectively. The overall impression is that prices are high in the two $4 \mathrm{~B} 4 \mathrm{~S}$ and $4 \mathrm{~B} 2 \mathrm{~S}$ designs.

The most notable feature of the data is that in the $2 \mathrm{~B} 4 \mathrm{~S}$ market structure, the two buyers clearly attempt to keep prices low through what we infer is a tacit bidding ring. However, they have difficulty maintaining low prices. Winning bid 


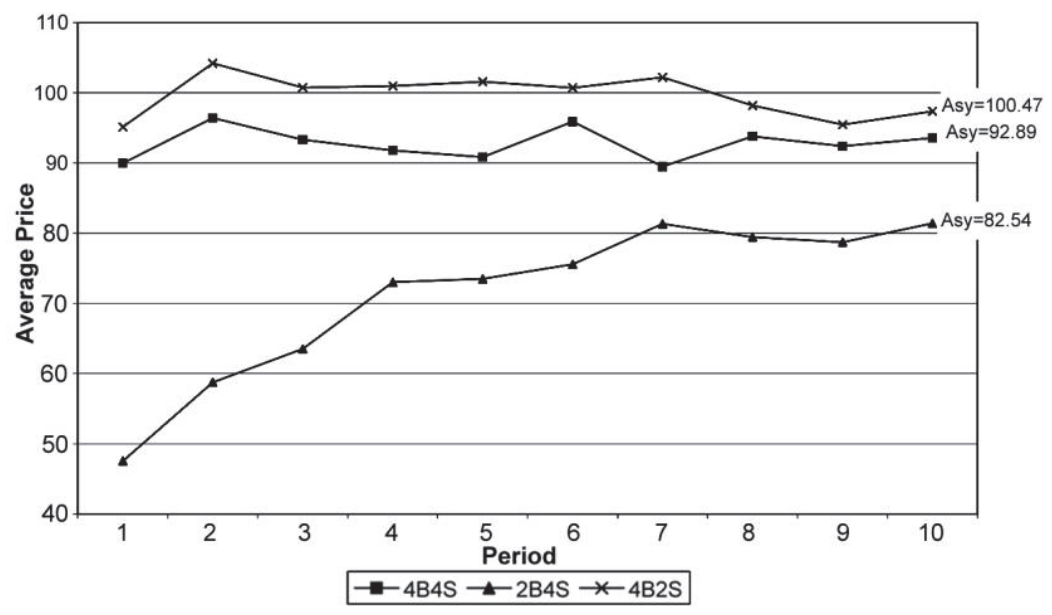

Figure 3. Average prices for alternative English auction treatments

prices start below 50 tokens. Toward the middle of the session, two-buyer prices rise to the mid-70-token range and end in the 80-token range. Two buyers appear able to stabilize prices near 80 tokens, a level that is well below that in the auctions that have four buyers. More profitable lower prices do not appear possible for the two buyers.

Why is a two-buyer bidding ring not capable of keeping prices low? We believe the answer to this question comes from the number of average trades reported in Figure 4. Here we focus on the 2B4S market design. While two buyers are able to win bids at prices below 80 , the four sellers are producing amounts that generally are less than 16 units, a level near the collusive-monopoly-predicted production (15.33 units). This puts pressure on buyers to raise bids in order to earn relatively large marginal profits. As bids increase, production increases to a level near that in the other designs. The $4 \mathrm{~B} 2 \mathrm{~S}$ treatment becomes a baseline, allowing us to observe how strongly four sellers react to low prices in the $2 \mathrm{~B} 4 \mathrm{~S}$ treatment. From the figure it appears that two sellers are able to exert monopoly control over production. Figure 4 shows that production is consistently restricted to an average of about 16 or 17 units. This level is in the range of what four sellers produce when they face two buyers. When production is endogenous, sellers adjust to low bid prices, and this presents difficulties for buyer collusion. The adjustment is remarkable; for the first half of the experiment, when the ring is attempting to keep prices relatively low, the quantity appears to be about 22 percent less than what is produced when there are four bidders and four sellers.

This observation is reinforced by the patterns of buyer earnings illustrated in Figure 5. For comparison purposes, average earnings are calculated as earnings per redemption table. In the $2 \mathrm{~B}$ market structure, each buyer is effectively work- 


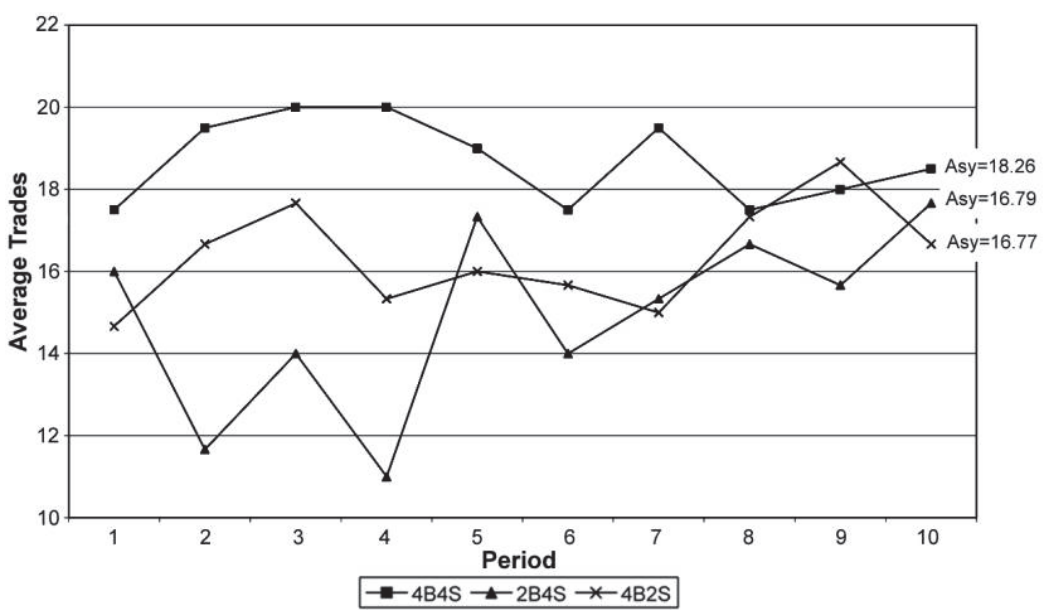

Figure 4. Average trades for alternative English auction treatments

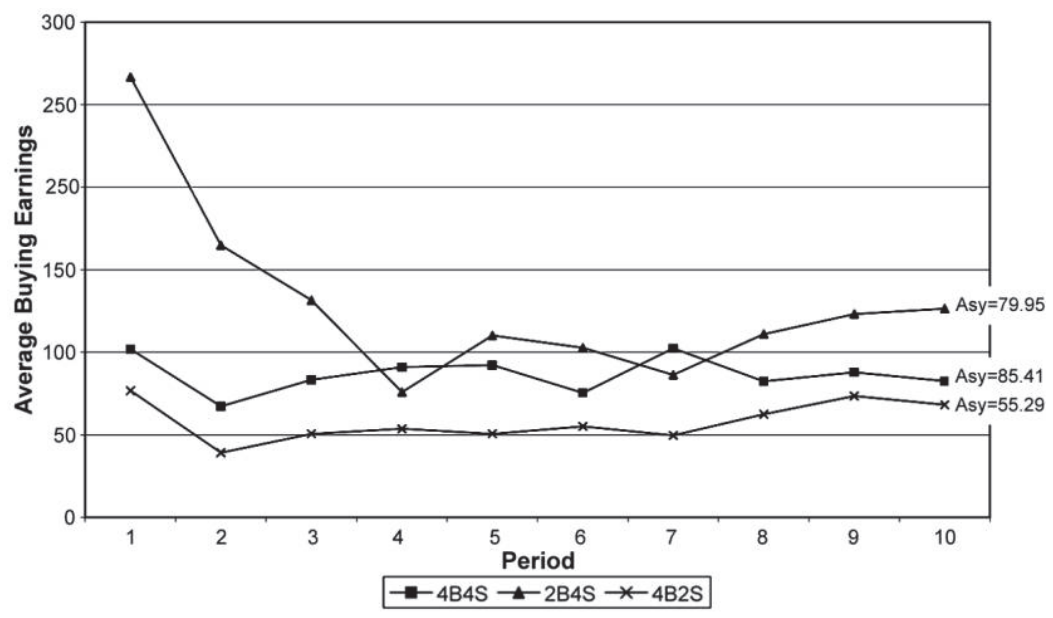

Figure 5. Average buyer earnings for alternative English auction treatments

ing with two redemption tables. Buyers can be thought of as middlemen, and redemption tables are earnings at their plant facilities. The $2 \mathrm{~B}$ market structure allows buyers to earn relatively large returns in the early part of a session, but then units produced/traded decline as a result of low initial prices and low seller earnings. By the middle of the experiment, earnings are near the levels of those from other market designs. Toward the end of the experiment, buyer earnings begin to trend upward because prices are stabilizing below 80 tokens and the 


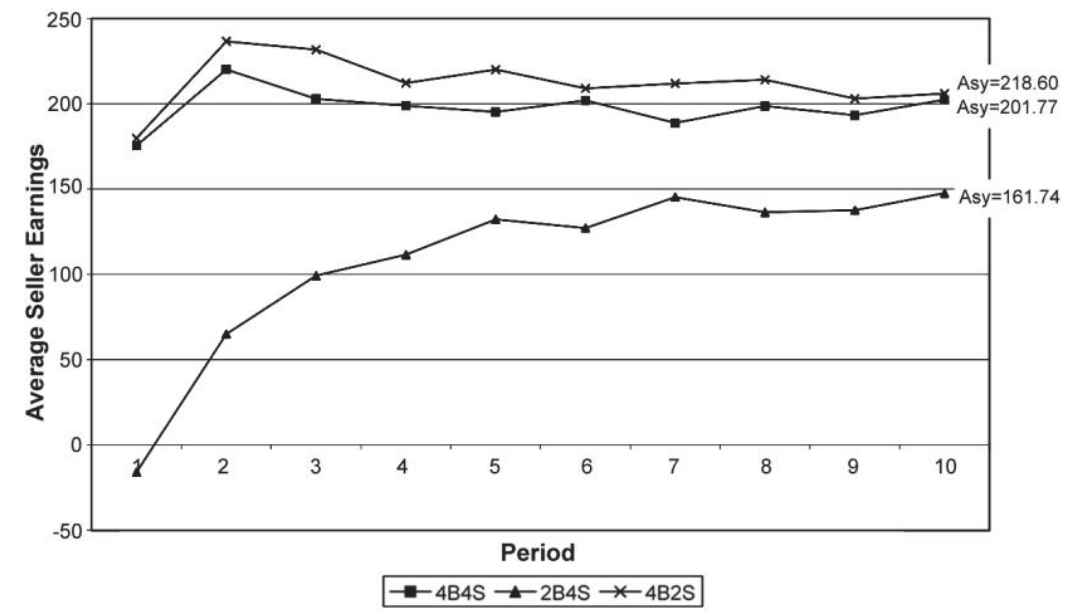

Figure 6. Average seller earnings for alternative English auction treatments

number of units produced and/or traded is relatively strong. We note that buyer earnings are lowest in the $2 \mathrm{~S}$ market structure, but the earnings in this design do not seem to be much different from those in the $4 \mathrm{~B} 4 \mathrm{~S}$ market. Buyer earnings in the experimental designs with four buyers are at levels close to that predicted by a profit-maximizing monopolist posting a price.

Seller earnings illustrated in Figure 6 explain why sellers react strongly to low bid prices in the 2B4S treatment. Consistent with calculations of buyer earnings, seller earnings are calculated on a per-cost-table basis when there are two sellers, as if each cost table represents a production plant. Average seller earnings in the 2B4S design begin negative and then gradually increase to about 150 tokens per seller. Even this level of return is about 50 tokens below that earned in the other market structures. The highest plant earnings for sellers occur in the 4B2S market structure, but these profits do not appear to be substantially greater than those in the other 4B4S markets. Overall, sellers do relatively well under the basic auction conditions constructed. Seller earnings in the 4B market structures are in the 200-token neighborhood, very near seller earnings predicted in the monopolist case (200.69 tokens). Buyer earnings are about 75 tokens. Hence, sellers earn about 166 percent more than buyers in this auction environment.

Finally, Figure 7 plots total earnings or total surplus in the market. The predicted range in surplus is from 1,200 tokens (the competitive level) to $1,092.80$ (for monopoly). The 4B market structures, by period 8 , generate about 1,100 tokens in total earnings-approximately equal to the monopoly level. The ratio $(1,100 / 1,200)$ is about .92 , relative to the competitive equilibrium. For most of the periods, the $2 \mathrm{~B}$ design is far less efficient than the $4 \mathrm{~B}$ markets. Buyers are exerting market power, and there are deadweight surplus losses. However, by 


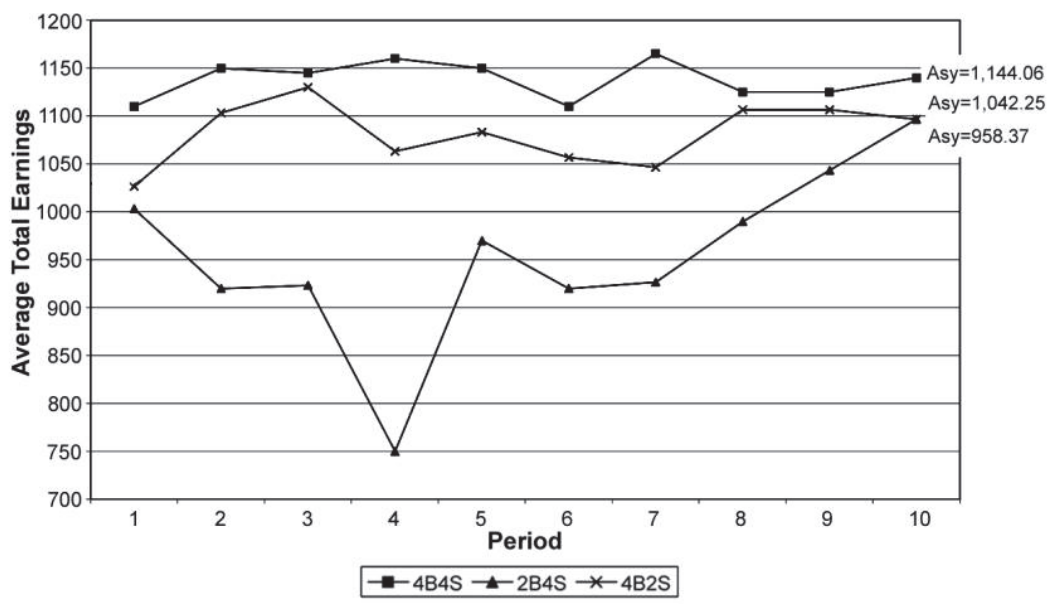

Figure 7. Average total earnings for alternative English auction treatments

period 7 total earnings are increasing and steadily increase until the total is about 1,100 by period 10 . Figure 7 indicates that buyer collusion in the $2 \mathrm{~B}$ design survives until about period 7 in the experiment and then collapses.

\section{Data Analysis: Convergence Model for the Seller-Active Auctions}

The purpose of this section is to discuss the convergence levels estimated from a statistical model that describes patterns in market outcomes-prices, quantities, and earnings. The plotted values described in the figures are used to estimate asymptote values. The competitive, Cournot, and pure monopoly predictions are used to benchmark trends. ${ }^{5}$ We estimate several versions of the following general convergence model (Ashenfelter and Genesove 1992; Noussair, Plott, and Reizman 1995):

$$
P_{i t}=B_{0}[(t-1) / t]+B_{1}(1 / t)+\sum_{j=1}^{i-1} \alpha_{j} D_{j}[(t-1) / t]+\sum_{j=1}^{i-1} \Gamma_{j} D_{j}(1 / t)+u_{i t},
$$

where $P_{i t}$ is the average sale price (or units traded, buyer earnings, seller earnings, or total earnings) across the three replications for all transactions for each of $t$ periods in auction treatment $i ; B_{0}$ is the fixed predicted asymptote of the dependent variable for the benchmark equilibrium (competitive, Cournot, or mo-

\footnotetext{
${ }^{5}$ Convergence models were estimated using the Cournot four- and two-seller predicted values as bases for market outcomes. The results from these models are discussed where appropriate but are not reported in table form. Alternative convergence models result in tests of statistical differences from the respective bases for each market outcome. Trends, magnitudes of starting and asymptote values, and tests of differences between treatments are approximately the same across the models using alternative bases for the market outcomes.
} 
nopoly prediction); $B_{1}$ is the predicted starting level of the data for the benchmark category; $t$ is the trading period $1, \ldots, 10 ; D_{j}$ is the dummy variable representing the $j$ th auction treatment $(4 \mathrm{~B} 4 \mathrm{~S}, 2 \mathrm{~B} 4 \mathrm{~S}$, and $4 \mathrm{~B} 2 \mathrm{~S})$; and $u_{i t}$ is the error term.

The dummy variable $\left(D_{j}\right)$ takes on the value of one when the dependent variable is from the $j$ th auction and is otherwise zero. The predicted convergence level or asymptote of the dependent variable is given by $B_{1}$ and is adjusted by the $\alpha_{j}$ coefficient. The asymptote values are of primary interest in this study, particularly how they differ from predicted equilibrium outcomes and across treatments. Separate equations were run using different benchmark equilibria (that is, competitive, Cournot, or monopoly values) as a base.

The experimental data generated over the 10 auction cycles may be serially correlated and heteroskedastic. Data may also be contemporaneously correlated between cross sections (market designs) owing to the same unit values or costs being used by subjects. The Parks (1967) method was used to estimate the model. This is an autoregressive model in which the random errors, $u_{i t}$, have structures $E\left(u_{i t}^{2}\right)=\sigma_{i i}$ (heteroskedasticity), $E\left(u_{i t} u_{j t}\right)=\sigma_{i j}$ (contemporaneously correlated), and $u_{i t}=\rho_{i} u_{i, t-1}+\varepsilon_{i t}$ (autocorrelation). The Parks method assumes a first-order autoregressive error structure with contemporaneous correlation between cross sections. The covariance matrix is obtained by a two-stage procedure leading to the estimation of model regression parameters by generalized least squares. (See SAS [1993, pp. 882-84] for details of this estimation method.) The use of the Parks method allows us to take account of the unique statistical problems resulting from the panel data sets that consist of time-series observations on each of the several cross-sectional units generated in our experiments.

Using the competitive equilibrium as a base, estimated asymptotes are reported next to the data plots in the figures as already described. Relative to the competitive and monopoly market equilibria, Table 2 shows the $\alpha_{j}$ estimates and standard errors. Tests relative to the Cournot benchmarks are not tabulated but are reported in the discussion below. Below, we highlight convergence model results.

Table 2 makes it plain that the competitive price at the intersection of supply and demand is not a good predictor of behavior. Prices in the 2B4S auctions are not significantly different from the 80 -token benchmark, but this is only because the bidding ring allows prices to rise in order to secure higher production levels. The coefficients relative to monopoly values in Table 2 show that the monopoly benchmark is also not a particularly good predictor of outcomes. However, prices are converging to high levels in the 4B2S auctions. It appears that sellers take advantage of their market power in the 4B2S auctions; buyers do not adjust and seem to remain competitive in their bidding behavior, resulting in the highest convergence level for price.

Relative to the Cournot predictions, the asymptote price in the $4 \mathrm{~B} 4 \mathrm{~S}$ auctions (92.89) is significantly higher than the $P_{\mathrm{c} 4}$ (86.11) prediction, and the 100.47 asymptote in the $4 \mathrm{~B} 2 \mathrm{~S}$ auctions is significantly higher than $P_{\mathrm{c} 2}(91.00)$. Arguably, 


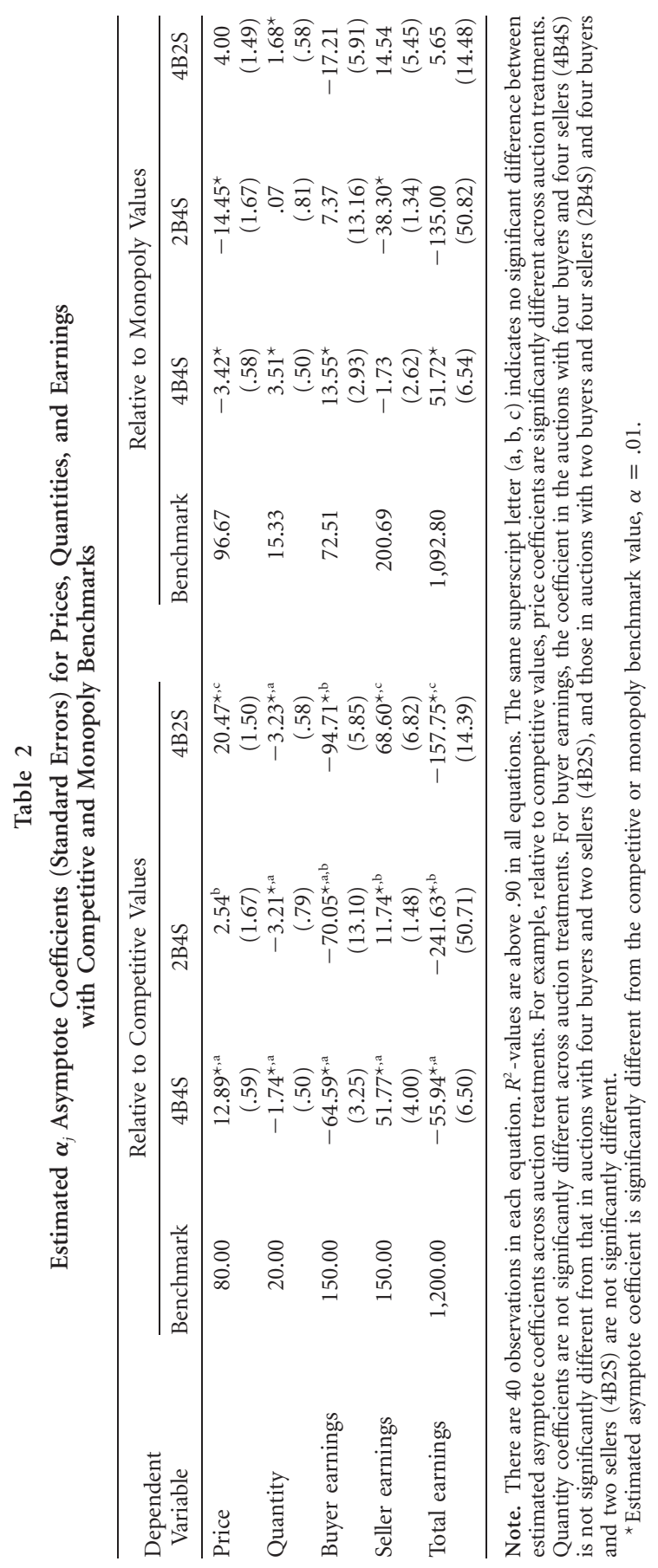


although statistically significant, these differences are not large. There is indication, supported by the quantity asymptotes, that the Cournot model is a reasonable predictor of behavior in the $4 \mathrm{~B} 4 \mathrm{~S}$ and $4 \mathrm{~B} 2 \mathrm{~S}$ auctions.

Whereas the price asymptotes across auction designs are significantly different, the convergence levels of quantities are remarkably similar. Table 2 shows no significant difference in quantities across the auctions. Convergence levels are generally lower than the competitive benchmark of 20 but significantly higher than the monopoly prediction. The Cournot benchmarks are good predictors of behavior. Asymptote trades in the 4B2S (16.77) are not significantly different from the Cournot two-seller prediction $\left(Q_{\mathrm{c} 2}=17.60\right)$, and trades in the $4 \mathrm{~B} 4 \mathrm{~S}$ auctions (16.79) are not significantly different from the Cournot four-seller benchmark of 19.56 .

The convergence model shows that, in the end, buyers in the 2B4S bidding ring auctions do not earn any more or less than buyers in the other auction designs. Table 2 coefficients for buyer earnings show that buyers as a group converge to earnings that are about 70 tokens below the competitive prediction of 150 tokens, which is not much different for buyers in the other auction designs. On the seller side of the ledger, the bidding ring is sufficiently weak by period 10 of the experiment that earnings are slightly above those in a perfectly competitive environment (161.74 versus 150). It is noticeable that across auction designs, sellers' earnings are converging to significantly different levels. Sellers as a group do relatively well in all of the auction designs. In the 4B4S and 4B2S auctions, sellers' earnings are not significantly different from the monopoly benchmark.

The last set of estimates in Table 2 reflect on market efficiency. The larger total earnings are, the larger total surplus is in the auction markets. Figure 7 shows that total earnings at the end of the experiments are very close. The substantial decrease in earnings shown in Table 2 for the $2 \mathrm{~B} 4 \mathrm{~S}$ auctions is due largely to the earlier periods when the bidding was stronger. Over the 10 trading periods, the ring clearly damages market efficiency. At the end, total earnings are in the 1,100-token range for all auction designs; efficiency is about 8 percent less than the competitive prediction.

\section{Summary and Implications}

This paper investigates collusive behavior in an English auction trading institution with endogenous production. Production levels and sales are described as a two-stage game. The amount for sale is known before the bidding begins. We believe that this type of market institution and information about the quantities for sale at the time of auction are prevalent in the sale of cattle, automobiles, wine, grains, timber, and art. When quantities are known and fixed, tacit cooperation is observed in two-buyer and four-buyer seller-inactive repeated auctions. Our seller-active auction designs have as many as four buyers and four 
sellers (4B4S). Two other repeated auction environments are created with either just two buyers (2B2S) or two sellers (4B2S).

Cournot behavior is a reasonable predictor of behavior in the symmetric 4B4S auction design. Production, then an auction sale, supports the Cournot model when there are similar numbers of buyers and sellers. Bidding rings develop when there are relatively few buyers. The lowest prices observed in any of the seller-active markets are in the buyer-concentrated auction structure (2B4S). Prices in this auction structure are on average about 20 percent lower than in the $4 \mathrm{~B} 2 \mathrm{~S}$ market and about 14 percent lower than in the $4 \mathrm{~B} 4 \mathrm{~S}$ market. There is, however, a pronounced upward trend in prices during the 10 auction periods in the $2 \mathrm{~B} 4 \mathrm{~S}$ auctions. Buyers are unable to maintain a strong ring owing to the control sellers have over units produced. Units produced and traded in this market are among the lowest in any treatment and are quite variable until the latter rounds of trading. The effect of a bidding ring is minimized when sellers can control the units coming up for sale in repeated auctions. Buyers learn this fairly quickly, and price stabilizes by period 7 in our laboratory auctions.

Sellers earn significantly more than buyers in the laboratory repeated English auctions with endogenous production, even in the buyer-concentrated market. Seller earnings are highest in the seller-concentrated structure, but their earnings in this market are not much different from the $4 \mathrm{~B} 4 \mathrm{~S}$ market. Seller earnings are consistently above the competitive norm across markets, except when a bidding ring is relatively strong in the $2 \mathrm{~B} 2 \mathrm{~S}$ auctions. In contrast, buyer earnings are consistently and significantly below the competitive prediction. The difference in earnings arises because sellers generally restrict production. The number of units brought to market, in fact, is no different from the collusive-monopoly prediction in the $2 \mathrm{~B} 4 \mathrm{~S}$ market and no different from the Cournot two-seller prediction in all markets.

We believe that the two-stage game of production in stage 1 and then an auction in stage 2 teaches sellers to reduce the total number of units produced. Combined buyer and seller earnings are small (or nonexistent) on the marginal units sold. As marginal units are sold, producers bear some risk of loss, especially without a reserve price. It is easy for a seller to decrease production in order to increase marginal returns and avoid potential losses. As sellers do this individually, they collectively see earning increase, and this reinforces the decision to bring fewer units to the auction. Production before the auction locks sellers into their decisions. Buyers in this environment do not make any commitments in advance of trading. They have the flexibility to seek marginal gains without any risk, and as a consequence, collectively remain more competitive. As quantity falls, the incentive to bid higher becomes greater, and this is the essence of why a bidding ring becomes weaker.

Bidding rings in a repeated English auction cannot be effectively sustained when producers can endogenously control the units coming to the auction. Producers simply reduce production when prices are low, and buyers' earnings are detrimentally affected. The resulting decrease in production leads to an in- 
crease in price. If production is in some way fixed or sunk (exogenous), then collusive behavior likely can be maintained. The commonly held belief of the susceptibility of English auctions to bidding rings therefore is conditional on whether sellers have some control over the units coming to the auction across production periods. If sellers in an auction can react to low prices by supplying fewer units in subsequent auctions, the bidding ring collapses, and there is competitive bidding among buyers.

\section{References}

Ashenfelter, Orley. 1989. How Auctions Work for Wine and Art. Journal of Economic Perspectives 3(3):23-36.

Ashenfelter, Orley, and Kathryn Grady. 2003. Auctions and the Price of Art. Journal of Economic Literature 43:763-86.

Ashenfelter, Orley, and David Genesove. 1992. Testing for Price Anomalies in Real-Estate Auctions. American Economic Review: Papers and Proceedings 80:501-5.

Athey, Susan, Jonathan Levin, and Enrique Seira. 2004. Comparing Open and Sealed Bid Auctions: Theory and Evidence from Timber Auctions. Working paper. Stanford University, Stanford, Calif.

Graham, Daniel A., and Marshall, Robert. C. 1987. Collusive Bidder Behavior at SingleObject Second Price and English Auctions. Journal of Political Economy 95:1217-39.

Kagel, John H. 1995. Auctions: A Survey of Experimental Research, Chap. 7 in The Handbook of Experimental Economics, edited by John H. Kagel and Alvin E. Roth. Princeton, N.J.: Princeton University Press.

Kwasnica, Anthony M., and Katerina Sherstyuk. 2007. Collusion and Equilibrium Selection in Auctions. Economic Journal 117:120-45.

Kreps, David M., and José A. Scheinkman. 1983. Quantity Precommitment and Bertrand Competition Yields Cournot Outcomes. Bell Journal of Economics 14:326-37.

Li, Jin, and Charles R. Plott. 2005. Tacit Collusion in Auctions and Conditions for Facilitation and Prevention: Equilibrium Selection in Laboratory Experimental Markets. Social Science Working Paper No. 1223. California Institute of Technology, Division of Humanities and Social Sciences, Pasadena.

McAfee, R. Preston, and John McMillan. 1992. Bidding Rings. American Economic Review 82:579-99.

Milgrom, Paul R., and Robert J. Weber. 1982. A Theory of Auctions and Competitive Bidding. Econometrica 50:1089-1122.

Myerson, Roger B. 1981. Optimal Auction Design. Mathematics of Operations Research 6:58-73.

Nelson, Jon P. 1995. Market Structure and Incomplete Information: Price Formation in a Real-World Repeated English Auction. Journal of Economic Behavior and Organization 27:421-37.

Noussair, Charles N., Charles R. Plott, and Rayword G. Reizman. 1995. An Experimental Investigation of the Patterns of International Trade. American Economic Review 85: 462-91.

Parks, Richmond W. 1967. Efficient Estimation of a System of Regression Equations When Disturbances Are Both Serially and Contemporaneously Correlated. Journal of the American Statistical Association 62:500-509. 
Phillips, Owen R., Dale J. Menkhaus, and Kalyn T. Coatney. 2003. Collusive Practices in Repeated English Auctions: Experimental Evidence or Bidding Rings. American Economic Review 93:965-79.

Porter, Robert H., and J. Douglas Zona. 1993. Detection of Bid Rigging in Procurement Auctions. Journal of Political Economy 101:518-38.

- 1999. Ohio School Milk Markets: An Analysis of Bidding. Rand Journal of Economics 30:263-88.

Riley, John G., and William F. Samuelson. 1981. Optimal Auctions. American Economic Review 71:38-92.

SAS. 1993. SAS/ETS User's Guide. Version 6. 2d ed. Cary, N.C.: SAS Institute, Inc.

Sherstyuk, Katerina. 2003. Some Results on Anti-competitive Behavior in Multi-unit Ascending Price Auctions. Pp. 185-98 in The Handbook of Experimental Economics Results, edited by Charles R. Plott and Vernon L. Smith. Amsterdam: Elsevier Press. 